$$
\int_{\text {ociales }}^{\text {cciones }}
$$

Notas sobre mercado y cooperativismo en el tercer milenio

José MANUel LASIERRA

ECONOMÍA APLICADA

UNIVERSIDAD DE ZARAGOZA

En este papel se esbozan algunas cuestiones sobre las posibilidades del cooperativismo como esquema económico en un contexto de cambio técnico y económico. Las cualidades que reúne el cooperativismo como sistema son contrarrestadas por la fuerza de la economía y la ideología mercantil de manera que las bondades de la teoría cooperativa no se ven correspondidas por la realidad económica y empresarial. En este sentido, y dados los valores innegables del modelo cooperativo, se realiza una breve alusión al papel de las administraciones en el apoyo al fomento del cooperativismo en un contexto descentralizado como el español.
\end{abstract}

Palabras clave: cambio económico, competitividad, externalidades sociales, políticas públicas.

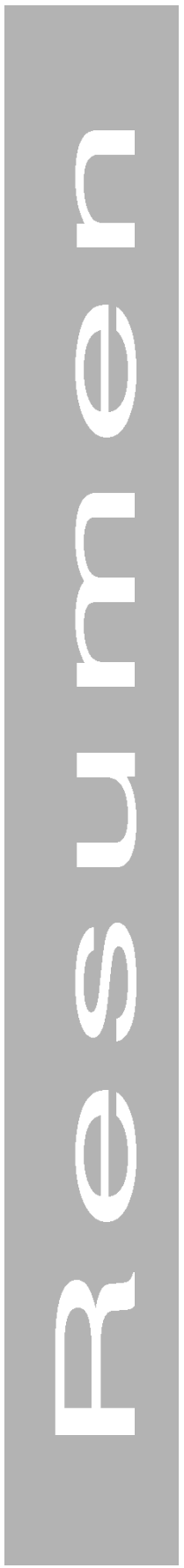




\section{Notas sobre mercado y coope- rativismo en el tercer milenio}

José Manuel Lasierra

El sistema productivo de los países desarrollados asiste desde finales del siglo $X X$ a un conjunto de cambios significativos en la organización de la producción, en las relaciones que se establecen entre el capital y el trabajo, incluso en algunos de los mecanismos de estabilización y bienestar social considerados como conquistas que no tenían vuelta atrás.

\section{Nuevos tiempos}

De acuerdo con Sengenberger y Campbell (1994) se pueden señalar los siguientes cambios:

a) Desplazamientos sectoriales de la producción, básicamente desde la agricultura y la industria a los servicios. Se manifiesta de dos maneras: en primer lugar, por el declive de actividades tradicionales como las denominadas industrias básicas y la aparición de una serie de sectores emergentes ligados a las telecomunicaciones y a la industria de la información; en segundo lugar, cambios dentro de la propia industria con un desplazamiento de las actividades manufactureras y el incremento de los servicios comerciales y para la producción.

b) El declive de la producción en masa en el mundo industrializado. La crisis de la denominada organización productiva "Fordista-Taylorista" basada en una definición estrecha de los puestos de trabajo y un factor trabajo poco cualificado preparado para el cumplimiento pasivo de las instrucciones recibidas. 
No está claro cual es el modelo que lo sustituye ni siquiera el grado de sustitución pero está originando cambios en el consumo, en los mercados y en la tecnología, y efectos entre estos aspectos entre si de forma que se difumina la causa inicial desencadenante.

c) Una nueva división internacional del trabajo con la aparición de nuevos países industrializados que comienzan por producciones ligeras basadas en trabajo barato y poco cualificado pero que posteriormente se van aproximando a los países más avanzados generando a su vez espacio para nuevas periferias.

d) La globalización de la economía caracterizada por la forma de operar hoy en día de las grandes compañías, la reducción de las barreras arancelarias para las mercancías y servicios que no dejan espacio para mercados cerrados y cautivos y la movilidad e interrelación de los mercados financieros y de capitales.

e) Un rediseño de la organización de las empresas que implica procesos de descentralización y externalización. Las grandes empresas a menudo asumen el papel de organizar la producción dentro de una red de empresas y las pequeñas empresas responden con la creación de los denominados distritos industriales.

La forma en que todas estas circunstancias afectan a la empresa demandan actuaciones que se vienen resumiendo en el amplio y ambiguo, por excesivamente utilizado, concepto de flexibilidad.Flexibilidad para adaptarse a entornos aceleradamente cambiantes e inciertos, flexibilidad que algunos identifican con desregulación.

\section{Flexibilidad: concepto y clases}

Una manera de analizar el desajuste estructural, la rigidez por oposición a flexibilidad, sería examinando la relación existente entre la evolución del empleo y la del producto agregado. Así una respuesta rápida y elevada del empleo ante incrementos de la producción indicaría un alto grado de "flexibilidad".

Sirvan unos datos de la economía española para ilustrar los desajustes del mercado de trabajo español: el umbral de crecimiento del PIB por debajo del cual se destruye empleo en la 
economía española se sitúa, para el periodo 1.985-1.992, en el $2.2 \%$. En la CEE en el mismo periodo se sitúa en el $1.6 \%$.

A nivel microeconómico, la flexibilidad puede conseguirse vía cantidades del factor trabajo o vía precios del mismo o una combinación de ambas. Se distingue la flexibilidad externa o numérica de la interna o funcional.

La flexibilidad externa o numérica se entiende como la capacidad de la empresa de demandar el volumen de empleo que necesita.Las razones pueden ser tanto de demanda como de la tecnología (de oferta) que se usa. Respecto a las primeras, se puede afirmar que ha aumentado la necesidad de flexibilidad numérica de las empresas como consecuencia de las mayores oscilaciones de la demanda y de que éstas se han hecho más impredecibles, y por la mayor competencia que estrecha los márgenes que permiten a las empresas soportar estructuras más o menos rígidas. Al mismo tiempo también se ha producido una aceleración del cambio técnico.

La gran diversidad de situaciones que obliga a las empresas a modificar la cantidad demandada de trabajo permite alternativas distintas a las aparentemente simples y poco costosas variaciones continúas del empleo. La elección de las diferentes posibilidades está en función del coste, sin despreciar cuestiones de índole macroeconómica y bienestar social de la comunidad.

La flexibilidad interna o funcional se define como la necesidad de la empresa de modificar la organización del trabajo y la asignación de los trabajadores a las distintas funciones.

Las razones que justifican la flexibilidad interna son prácticamente las mismas que las de la flexibilidad externa:de demanda y de oferta, éstas últimas asociadas con el cambio tecnológico. Estas razones conducen a lo que hemos llamado la crisis del modelo "Fordista-Taylorista" de producción caracterizado por una gran especialización de los factores productivos tanto de capital como de trabajo, pensado para la producción en gran escala estandarizada.Las diversas tareas están perfectamente definidas, los puestos de trabajo claramente delimitados, la organización es jerárquica y los salarios se suelen asignar más a los puestos de trabajo que a las personas que los desempeñan. Aunque existan unos componentes "variables" del salario, para estimular una mayor productividad, el ritmo del trabajo se determina fundamentalmente por la empresa. 
El nuevo modelo de organización productiva que se vislumbra se caracteriza por una polivalencia de los factores productivos: la maquinaria se utiliza para obtener diversos productos y ésto exige un factor trabajo adaptativo, colaborador y más cualificado. El factor trabajo deja de considerarse un coste y se empieza a hablar de capital humano, general o específico, cuya utilización exige una remuneración pero a cuya formación también contribuye la empresa. El trabajo, además de input, tiene una parte de output.

La necesidad de capital humano específico constituye una razón adicional en la demanda de flexibilidad interna o funcional, tanto para su "uso" como para su generación.

Factores productivos flexibles demandan sistemas de organización interna de la empresa flexibles. Es probable que este sistema de producción flexible exija también flexibilidad exterior o numérica pero en general se puede encontrar un grado de sustituibilidad entre ambas. Si se añade la posible flexibilidad en precios de los factores, la demanda de flexibilidad numérica podría reducirse notablemente.

Se ha señalado que factores flexibles suelen exigir estructuras organizativas flexibles. La crisis del modelo TayloristaFordista no termina de rechazar el modelo de estructuración jerárquica de las organizaciones en lo que se refiere a los flujos de información, que sólo circulan verticalmente, y a las relaciones de autoridad y control, basadas en la separación entre capital y trabajo.

El modelo de organización interna flexible apunta a la necesidad de alguna forma de participación que mejora los flujos de información, disminuye los costes de control y, en términos generales, obtiene aumentos de productividad.

La participación permite combinaciones de flexibilidad en la estructura del empleo y de la organización productiva que pueden mejorar la eficiencia y la equidad.

Aunque no existen pruebas concluyentes acerca de la superioridad de las formas organizativas participativas sobre las jerarquizadas, los resultados de algunos estudios (Blinder,1.990) parecen inclinarse en favor de las primeras. Por otra parte, la participación puede realizarse de muy diversas maneras. Lo que se observa es una tendencia en la práctica de las empresas a establecer sistemas de participación de los trabajadores, por delante incluso del debate teórico sobre esta modalidad organizativa. 
Lo que en principio pudo ser una parte variable del salario en el ámbito individual como forma de la empresa de conseguir un mayor esfuerzo de los trabajadores, se ha convertido en una estrategia más general de buscar una mayor identificación de los trabajadores con los intereses generales de la empresa haciéndoles partícipes en alguna medida de las ganancias o beneficios de la empresa, con la perspectiva menos individualizada y más globalizada, de considerar equipos.

Las transformaciones de los procesos productivos aludidas seguramente constituyen el motivo de estos cambios y especialmente el de las crecientes y variadas formas de participación en los asuntos de la empresa. La ampliación y aumento de la diversidad de las tareas en la empresa dificulta a un cuadro directivo establecer con precisión las cuestiones a resolver y esto implica aumentar la discrecionalidad de los trabajadores, en cuanto a la ejecución de sus funciones, y una disminución de la función supervisora. En definitiva se demanda un mayor flujo de información y se relajan las funciones de control por el autocontrol global compensado por la participación en los beneficios.

\section{Mercados y funciones empresariales}

Se considera que el mercado es el mecanismo más eficiente de asignación de recursos por lo que se apela al mismo en esta situación de cambio productivo. La visión más generalizada de los objetivos de la empresa es que buscan el máximo beneficio. Sin embargo en estos tiempos de profundas transformaciones se vuelve la vista a la empresa en demanda de más y nuevos resultados, entre otros empleo. Veamos como responden los mercados perfectos a las empresas que buscan algún objetivo de carácter social (empleo, formación, promoción social de los empleados y del entorno, protección del medio ambiente). Tanto North (1985), con sus referencias a la inclinación que tienen los agentes a comportarse oportunistamente, como Baumol y Blackman (1993) muestran las dificultades de los mercados perfectos para generar este tipo de comportamientos. Lo que podría ser considerado por la sociedad como buena contribución al bienestar general, el crear em- 
pleo, formar capital humano, soportar parte de los costes del ajuste productivo, mejorar el medio ambiente, constituye en términos recogidos por Baumol y Blackman (1993) un despilfarro, y sus efectos los describen de esta manera: "El teorema de la exclusión del despilfarro se basa en la vulnerabilidad de las empresas establecidas frente a la pérdida de mercado, ante cualquier rival más eficiente $y$, por tanto, capaz de ofrecer precios más bajos. Esto es, la ausencia de costes de entrada y salida bajo condiciones de competencia perfecta o impugna bilidad impide toda ineficiencia, porque cualquier empresa que consienta un gasto despilfarrador no podrá soportar durante mucho tiempo las incursiones de las nuevas que entran en el mercado y son más eficientes".

No se puede esperar por tanto una actitud benevolente de la empresa en una situación de mercados perfectos. Esto conduce a diseñar un sistema que facilite la consecución de alguno de esos objetivos sociales y que puede concretarse como disposiciones normativas que afecten por igual a todos los agentes porque esos beneficios sociales incrementan los costes de las empresas y que éstas mejoran sus resultados si tienen menores costes, por lo que debe situarse a todas las empresas en igualdad de condiciones.

\section{La cooperación, eficiencia y equidad}

Sabemos de la filosofía cooperativa, de sus principios y de su práctica, que las empresas cooperativas tienen diversos y prioritarios objetivos sociales. También se ha podido deducir de todo lo anterior, que el modelo de empresa cooperativa posee unos niveles de flexibilidad, se diría, que de las tres clases superior a la empresa mercantil, por tanto mejor adaptado para estos tiempos tan agitados. Sin embargo su presencia es muchísimo menor. Las causas de carácter sociológico, cultural, psicológico son sin duda ciertas pero complejas de delimitar. En este sentido no se pueden desdeñar con ligereza los patrones de funcionamiento del homo oeconomicus que definiera Adam Smith caracterizado por la búsqueda de su propio interés, desde una óptica individualista. El desarrollo de esos patrones en la acción colectiva que han realizado autores como Olson (1992) también 
alumbraría las razones de por qué la empresa cooperativa tiene una esperanza de vida menor, (Ben-Ner, 1988).

Existen otras de carácter económico como los desajustes en el mercado de trabajo o el comportamiento de los mercados de capitales ante empresas participativas que explican esta posible inferioridad de condiciones.

Si consideramos la posibilidad de intervención en el fomento del cooperativismo para el caso español, hay que señalar que la libertad de empresa y el principio de unidad de mercado en nuestra Constitución establece que la normativa no puede determinar discriminaciones en favor de unos agentes frente a otros aunque en el caso que nos ocupa, las cooperativas además de ser empresas tan eficientes como las sociedades mercantiles tienen diversos objetivos sociales y generan externalidades sociales positivas para la comunidad. De hecho en la práctica son escasamente operativas las medidas de carácter normativo o incluso fiscal que discriminen positivamente a las cooperativas.

Esto mismo ocurre si se pretende actuar desde el ámbito autonómico. En el artículo 149 de la Constitución Española se disponen las materias sobre las que el Estado se reserva actuaciones exclusivas con los objetivos de garantizar la unidad e identidad del sistema económico, asegurar la dirección y unicidad de la política económica nacional y regular los sectores en los que existen importantes externalidades entre las diversas autonomías. Por estas razones, materializadas en una relación explícita de instrumentos, la legislación que afecte a materias socioeconómicas, aunque sea posible ejercer desde el ámbito autonómico, como las materias sobre cooperativismo, no supondrá en la práctica cambios normativos sustanciales que generen ventajas claras de unas comunidades sobre otras o respecto a otras formas jurídicas de empresa.

Sin embargo quedan algunos resquicios que no pueden despreciarse que irían en la línea del fomento del cooperativismo. El destino y la dotación de los fondos de promoción y la acción intercooperativa con apoyo presupuestario explícito de la comunidad autónoma podrían constituir actuaciones propias y altamente positivas aunque la totalidad de los beneficios sociales, se recuerda, no permanecerían en el sitio donde se producen. 


\section{Bibliografía}

BAUMOL, W. y BLACKMAN, S. (1993): Mercados perfectos y vir tud natural. La ética en los negocios y la mano invisible. Celeste Ediciones. Madrid.

BEN-NER, A. (1988): «The life cycle of worker-owned firms in market economies». Journal of Economic Behavior and Organization, 10, pp. 287-313.

BLINDER, A.(1990) (Ed.): Paying for productivity. The Brookings Institutions. New York.

NORTH, D. (1985): Estructura y cambio en la historia econó mica. Alianza Editorial. Madrid.

OLSON, M. (1992): La lógica de la acción colectiva: bienes pú blicos y teoría de grupos. Limusa. México.

SENGENBERGER, W. y CAMPBELL, D. (1994) (Ed.): The role of labour standars in industrial restructuring. ILO. Geneve. 